\title{
Assessment of ventilatory neuromuscular drive in patients with obstructive sleep apnea
}

L.R.A. Bittencourt, S.M.T. Moura, M.C. Bagnato, L.C. Gregório, S. Tufik and L.E. Nery

\author{
Divisão Respiratória and Departamento de Psicobiologia, \\ Escola Paulista de Medicina, Universidade Federal de São Paulo, \\ São Paulo, SP, Brasil
}

\section{Correspondence \\ L.E. Nery \\ Divisão Respiratória e \\ Departamento de Psicobiologia \\ EPM, UNIFESP \\ Rua Botucatu, 925 \\ 04024-002 São Paulo, SP \\ Brasil \\ Fax: 55 (011) 572-5092 \\ Research partially supported by FAPESP, CNPq and AFIP.}

Received January 28, 1997 Accepted January 5, 1998

\section{Abstract}

The presence of abnormalities of the respiratory center in obstructive sleep apnea (OSA) patients and their correlation with polysomnographic data are still a matter of controversy. Moderately obese, sleep-deprived OSA patients presenting daytime hypersomnolence, with normocapnia and no clinical or spirometric evidence of pulmonary disease, were selected. We assessed the ventilatory control and correlated it with polysomnographic data. Ventilatory neuromuscular drive was evaluated in these patients by measuring the ventilatory response (VE), the inspiratory occlusion pressure $\left(\mathrm{P}_{.1}\right)$ and the ventilatory pattern (VT/TI, TI/TTOT) at rest and during submaximal exercise, breathing room air. These analyses were also performed after inhalation of a hypercapnic mixture of $\mathrm{CO}_{2}\left(\Delta \mathrm{P}_{1} / \Delta \mathrm{P}_{\mathrm{ET}} \mathrm{CO}_{2}, \Delta \mathrm{VE} / \Delta \mathrm{P}_{\mathrm{ET}} \mathrm{CO}_{2}\right)$. Average rest and exercise ventilatory response (VE: 12.2 and $32.6 \mathrm{l} /$ min, respectively), inspiratory occlusion pressure $\left(\mathrm{P}_{.1}: 1.5\right.$ and 4.7 $\mathrm{cmH}_{2} \mathrm{O}$, respectively), and ventilatory pattern (VT/TI: 0.42 and $1.09 \mathrm{l} /$ s; TI/TTOT: 0.47 and $0.46 \mathrm{l} / \mathrm{s}$, respectively) were within the normal range. In response to hypercapnia, the values of ventilatory response $\left(\Delta \mathrm{VE} / \Delta \mathrm{P}_{\mathrm{ET}} \mathrm{CO}_{2}: 1.511 \mathrm{~min}^{-1} \mathrm{mmHg}^{-1}\right)$ and inspiratory occlusion pressure $\left(\Delta \mathrm{P}_{.1} / \Delta \mathrm{P}_{\mathrm{ET}} \mathrm{CO}_{2}: 0.22 \mathrm{cmH}_{2} \mathrm{O}\right)$ were normal or slightly reduced in the normocapnic OSA patients. No association or correlation between ventilatory neuromuscular drive and ventilatory pattern, hypersomnolence score and polysomnographic data was found; however a significant positive correlation was observed between $\mathrm{P}_{.1}$ and weight. Our results indicate the existence of a group of normocapnic OSA patients who have a normal awake neuromuscular ventilatory drive at rest or during exercise that is partially influenced by obesity.
Key words

- Ventilatory neuromuscular drive

- Sleep apnea

- Polysomnography

- Ventilatory control 


\section{Introduction}

Several studies have shown a reduction of ventilatory drive in patients with obesityhypoventilation syndrome (1-4). However, it is not yet clear whether this abnormality is primary or secondary in its origin.

In contrast, alterations of the respiratory center in obstructive sleep apnea (OSA) are still controversial. Some investigators believe that obesity could stimulate the ventilatory drive. This hypothesis was raised by Sampson and Grassino (5) for obese patients without OSA with a normal ventilatory pattern, but with increased inspiratory occlusion pressure. The same has not been observed by others (6), who showed normal hypercapnic ventilatory response in these subjects. Studies of obese OSA patients have indicated a reduced hypercapnic ventilatory response compared to obese subjects without OSA (7) or when an inspiratory load was imposed (8).

The role of upper airway obstruction in decreasing the ventilatory drive of OSA patients has been suggested in studies in which tracheostomy (9) or continuous positive airway pressure (CPAP) (10) improved the hypercapnic response. Also, sleep deprivation as the cause of reduction in the hypercapnic ventilatory response has been shown to occur in normal subjects (11-13). The disparity of data reported in these studies is probably due to the use of different methods and a heterogeneous patient series.

In the present study we evaluated OSA patients presenting the following characteristics: a) moderate obesity (14); b) sleep deprivation and fragmentation reflected by reduced sleep efficiency and altered sleep architecture, with resulting daytime hypersomnolence assessed by a hypersomnolence score (15), and c) normocapnia with no spirometric alterations which might indicate obstructive or restrictive ventilatory disturbances.

The major objective of the present study was to evalute the possible abnormalities of the respiratory center by assessing ventilatory response, inspiratory occlusion pressure $\left(\mathrm{P}_{.1}\right)$ and ventilatory pattern at rest (breathing either room air or a hypercapnic mixture) and during a metabolic increase induced by exercise. We also attempted to correlate possible alterations of these variables with polysomnographic findings.

\section{Patients and Methods}

\section{Subjects}

Twenty-two patients with a diagnosis of OSA who presented an apnea/hypopnea index (AHI: number of apneas and hypopneas/ total sleep time) above 15 were included in the study. These patients were referred from the Sleep Disorders Section of the Respiratory Division, Universidade Federal de São Paulo, and were compared with normal subjects studied by Moura et al. (16) to determine normal values for the variables $\mathrm{P}_{.1}$ and ventilatory pattern at rest and during submaximal exercise, following the same protocol. The hypercapnic ventilatory response was compared to the normal range reported by Burki (17).

Exclusion criteria were 1) degree III of obesity: body mass index (BMI) above 40 $\mathrm{kg} / \mathrm{m}^{2}$ (14); 2) clinical diagnosis of chronic obstructive pulmonary disease, asthma, bronchiectasis, obstructive or restrictive ventilatory insufficiency (18) assessed by simple spirometry; 3) hypercapnia, i.e., partial arterial carbon dioxide blood pressure $\left(\mathrm{PaCO}_{2}\right)$ above $45 \mathrm{mmHg}$ determined by arterial gasometry; 4) diseases that may lead to secondary OSA, such as hypothyroidism, acromegaly, Cushing syndrome, and other disturbances that may hinder the patient's ability to perform the exercise, such as peripheral vascular insufficiency, bone and/or joint and muscle alterations, cardiac insufficiency and acute coronary insufficiency. 


\section{Protocol}

Clinical evaluation. A modified questionnaire (15) containing questions about sleep, snoring, nocturnal apneas and daytime hypersomnolence was used. Answers were scored as $0=$ never, $1=$ rarely, $2=$ occasionally, and $3=$ frequently. The severity of hypersomnolence was classified as follows: 0.5 to $1=$ mild, up to $2=$ moderate, and greater than 2 to $3=$ severe.

Otorhinolaryngologic evaluation consisted of nasofibroscopy using an FLT-S Machida (Tokyo, Japan) apparatus connected to a monitor, a NISCO G10 CCD-25 control camera and a Machida RH 150 TL source (Japan). During examination, the patient was seated at a $45^{\circ}$ angle in dorsal inclination during both spontaneous breathing and Müller maneuver. Following these procedures, abnormalities of nasal cavities, oropharynx, rhinopharynx and hypopharynx were recorded.

Polysomnographic recording. Polysomnography was carried out throughout the night. The apparatus consisted of a sleep analyzer computer (SAC, version 9.2, Oxford Instruments, Inc., Tampa FL, USA). Thirteen channels were distributed as follows: 2 for electroencephalography, 2 for the oculogram, 1 for chin electromyography, 2 for tibial electromyography, 1 for electrocardiography, 1 for airflow, 2 for thoracicabdominal movements, 1 for pulse oxymetry and 1 for detection of body position. The system automatically analyzes sleep stages using the criteria of Rechtschaffen and Kales (19), detecting artifacts and arousals.

At the end of the recording period, a physician trained in polysomnographic reading reanalyzed the computer-generated staging following the criteria of Rechtschaffen and Kales (19) and making the necessary alterations. The normal values used for analysis of sleep variables were those proposed by Carskadon and Dement (20), and those for respiratory events were those of
Guilleminault (21).

The variables analyzed during polysomnography were sleep efficiency (ratio of total sleep time/total recording time), sleep stages 3, 4 and REM (percentage of sleeping time), AHI and percentage of total recording time with oxyhemoglobin saturation below $85 \%$.

Spirometry and flow-volume curve. The Diagnostic System Med Graphic MGC-CPx (St. Paul, MN, USA) set on the flow mode was used. The difference in pressure in a linear pneumotachograph (Hans Rudolph, model 3800, Kansas City, MO, USA) was calculated to measure airflow. Patients were submitted to the test at rest, in a sitting position and breathing room air. Predicted values were based on the formulas reported by Knudson et al. (22) and Cherniack and Raber (23). A series of at least 3 measurements were obtained. Curves were accepted by the system when the criteria determined by the American Thoracic Society (24) were reached. We analyzed as percentage of predicted values the forced vital capacity $(\% \mathrm{FVC})$, the ratio of forced expired volume in the first second $\left(\mathrm{FEV}_{1}\right)$ over FVC $\left(\mathrm{FEV}_{1} /\right.$ $\mathrm{FVC}$ in \%) and the ratio of forced expired flow at $50 \%$ of $\mathrm{FVC}$ / forced inspired flow at $50 \%$ of $\mathrm{FVC}\left(\mathrm{FEF}_{50 \%} / \mathrm{FIF}_{50 \%}\right)$.

Maximal voluntary ventilation. After the determination of the flow-volume curves, patients were submitted to at least 3 maximal voluntary ventilation (MVV) maneuvers, which consisted of inhalations and exhalations using the highest possible tidal volume and respiratory frequency for a period of 15 s. Predictive values were those used by Cherniack and Raber (23).

Measurements of maximal inspiratory (MIP) and expiratory pressures (MEP). On the same day, following a 30-min period of rest, patients were instructed to perform maneuvers of maximum inspiratory and expiratory pressures measured with a manovacuometer $\left( \pm 150 \mathrm{cmH}_{2} \mathrm{O}\right.$; IMEBRAS, São Paulo, SP, Brazil) and the best of 10 maneu- 
vers was considered for analysis. The criteria of acceptance were those determined by Ringqvist (25), whereas normal range values of MIP and MEP were based on those reported by Wilson et al. (26).

Arterial blood gases and $\mathrm{pH}$ measurements. Arterial blood was anaerobically collected with the patient at rest and breathing room air. Blood gases $\left(\mathrm{PaO}_{2}\right.$ and $\left.\mathrm{PaCO}_{2}\right)$ and $\mathrm{pH}$ were determined using an ABL 330 apparatus (Radiometer, Copenhagen, Denmark), and normal $\mathrm{PaO}_{2}$ values were calculated using regression of these variables, according to age, as established by Mellengaard (27).

Ventilatory and metabolic evaluation at rest and during the submaximal exercise test. The exercise test was performed on the same day employing an electromagnetic cycloergometer (Collins-Pedalmate, Braintree, MA, USA) and variables were monitored with a cardioscope and an electrocardiograph (FUNBEC, São Paulo, SP, Brazil). Pulse oximetry was determined with an oximeter (Sensor Medics, Oxyshuttle TM, Anahein, CA, USA). Ventilatory and metabolic variables (tidal volume (VT), respiratory rate, minute ventilation (VE), oxygen uptake and carbon dioxide output $\left.\left(\mathrm{VCO}_{2}\right)\right)$ were analyzed by the Med Graphic MGCCPx system set on the metabolic mode. Ventilation and $\mathrm{VCO}_{2}$ were obtained breath-bybreath by integration of flow and volume and the $\mathrm{CO}_{2}$ signal, as previously described $(28,29)$. A period of $2 \mathrm{~min}$ at rest was followed by exercise which began with a 0 Watt load for 2 min followed by an increment of 25 Watts for $5 \mathrm{~min}$, and a further increment of 25 Watts (total of 50 Watts) for another 5 min. Electrocardiography, oxyhemoglobin saturation and systemic arterial blood pressure were also measured simultaneously during each period.

Determination of ventilatory pattern and inspiratory occlusion pressure. Analysis of the ventilatory pattern was performed at rest and during the different exercise loads and the values obtained were compared to those reported by Moura et al. (16). We analyzed VT, VE, respiratory rate, inspiratory time (TI)/total cycle time (TTOT) ratio and the VT/TI ratio.

During assessment of $\mathrm{P}_{.1}$, patients were acoustically and visually isolated from the environment (16). Ventilatory assessment was performed with the patient breathing through a mouthpiece connected to a twoway valve (Rudolph 2700) of low resistance and $90 \mathrm{ml}$ of dead space. Inspiratory flow rate was measured with a Fleisch pneumotachograph coupled to a pressure transducer (Valydine MP, $45.1 \pm 2.0 \mathrm{cmH}_{2} \mathrm{O}$ ). The generated electric signal was recorded with a Beckman polygraph (model R-411) as inspiratory flow and sent to a Thompson integrator (Montreal, Canada), which generated another electric signal that corresponded to VT on the polygraph. After a 2-min period of adaptation, we began the recording of tidal volume and inspiratory flow with the polygraph set at a speed of $10 \mathrm{~mm} / \mathrm{s}$. $P_{.1}$ was recorded at a speed of $100 \mathrm{~mm} / \mathrm{s}$, using an inspiratory occlusion at the level of functional residual capacity produced by a pneumatic valve for a period of $300 \mathrm{~ms}(16,30)$. This procedure was repeated as many times as necessary to obtain 5-10 technically acceptable $\mathrm{P}_{.1}$ curves (with no flow or volume alteration), with at least 4 curves of flow and tidal volume preceding each one. Bizarre curves were excluded from $\mathrm{P}_{.1}$ calculation $(16,30)$.

$\mathrm{P}_{.1}$ values were obtained, after discarding the first $50 \mathrm{~ms}$, by measuring the pressure variations of the occluded airway during inspiration during the subsequent $100 \mathrm{~ms}$. This assessment was performed at rest and during the 3rd (25 Watts) and 6th min (50 Watts). Normal ranges were those determined by Moura et al. (16) in our laboratory.

Steady-state $\mathrm{CO}_{2}$ inhalation test. The patient, sitting and wearing a nasal clip, breathed through a mouthpiece connected to a twoway Rudolph 2700 valve coupled to a $120-1$ 
Douglas balloon containing an $8 \% \mathrm{CO}_{2}$ and $42 \% \mathrm{O}_{2}$ mixture. The system used for $\mathrm{P}_{.1}$ measurement was connected to the airways. The expiratory port was in contact with the environment. $P_{.1}$ was assessed after 3 min of inhalation of the mixture. At the end of the 5 th min, expiratory air was collected for 1 min through a connection with a 120-1 Tissot gasometer (Warren E. Collins, Inc., Braintree, MA). The displacement generated by the volume of air obtained under BTPS conditions was recorded. Simultaneously, the end tidal $\mathrm{CO}_{2}$ expired fraction was measured with an infrared $\mathrm{CO}_{2}$ analyzer (Sensor Medics, model LBII) whose output signal was recorded with a polygraph (Beckman, model $\mathrm{R}$ 411). The end tidal $\mathrm{CO}_{2}$ partial pressure $\left(\mathrm{P}_{\mathrm{ET}} \mathrm{CO}_{2}\right)$ was then calculated (16). The values of $\Delta \mathrm{P}_{.1} / \Delta \mathrm{P}_{\mathrm{ET}} \mathrm{CO}_{2}$ and $\Delta \mathrm{VE} / \Delta \mathrm{P}_{\mathrm{ET}} \mathrm{CO}_{2}$ reported by Burki (17) were used as reference values.

This study was approved by the Ethics Committee of Hospital São Paulo and informed consent was obtained from the subjects.

\section{Statistical analysis}

The ventilatory neuromuscular drive, respiratory impedance and ventilatory pattern of patients and normal volunteers from our laboratory (16) were compared by the MannWhitney U-test (31).

In a second phase of the analysis, patients were separated according to the median values of the score of hypersomnolence and polysomnographic variables, and the ventilatory drive and the respiratory pattern of these two subgroups were compared by the Mann-Whitney U-test.

The possible association between neuromuscular ventilatory drive $\left(\mathrm{P}_{.1}, \mathrm{P}_{.1} / \mathrm{VCO}_{2}\right.$, $\Delta \mathrm{P}_{1} / \Delta \mathrm{P}_{\mathrm{ET}} \mathrm{CO}_{2}$ and $\left.\Delta \mathrm{VE} / \Delta \mathrm{P}_{\mathrm{ET}} \mathrm{CO}_{2}\right)$ and hypersomnolence score, and polysomnographic variables (sleep efficiency, arousals, AHI and oxyhemoglobin saturation) was determined by comparing their median values by the chi-square test or the Fisher exact test (31).

The Spearman correlation test was used to evaluate the correlation between ventilatory drive variables and weight, hypersomnolence score, AHI and minimum oxyhemoglobin saturation (31).

\section{Results}

The group of patients consisted of 17 men and 5 women ranging in age from 32 to 63 years, weighing 63 to $123 \mathrm{~kg}$, and ranging in height from 151 to $178 \mathrm{~cm}$, which resulted in a BMI of 25.5 to $39.3 \mathrm{~kg} / \mathrm{m}^{2}$. Median values are shown in Table 1 . The control group (16) consisted of 10 men ranging in age from 23 to 32 years, weighing 57 to $85 \mathrm{~kg}$ and ranging in height from 160 to $180 \mathrm{~cm}$. The OSA patients were older and heavier than normal subjects.

The scores obtained from the clinical questionnaire showed that 4 patients presented mild hypersomnolence (score $>0.5$ and <1), 14 presented moderate hypersomnolence (score $>1$ and $<2$ ), and 4 severe hypersomnolence (score $>2$ ). None of the normal subjects complained of hypersomnolence.

Table 1 - Physical characteristics and polysomnographic data of OSA patients.

BMI: Body mass index; TST: total sleep time; TRT: total recording time; SPT: sleep period time, defined as the result of TST subtracted from the initial and final latencies; AHI: apnea/hypopnea index; $\mathrm{SaO}_{2}<85 \%$ : percentage of TRT with oxyhemoglobin saturation below $85 \%$.

\begin{tabular}{|c|c|c|}
\hline Variable & Median & Range \\
\hline Age (years) & 47 & $32-63$ \\
\hline Weight (kg) & 90.4 & $63-123.5$ \\
\hline Height (cm) & 167.7 & $151-178$ \\
\hline BMI $\left(\mathrm{kg} / \mathrm{m}^{2}\right)$ & 32.6 & $25.5-39.4$ \\
\hline TST/TRT & 71.5 & 46.1-93.2 \\
\hline Stages (\%SPT) 3 and 4 & 3.5 & $0-29$ \\
\hline REM & 12.7 & $2-42.8$ \\
\hline $\mathrm{AHI}$ & 48 & $16.2-89.5$ \\
\hline $\mathrm{SaO}_{2}<85 \%$ & 22 & $0-51$ \\
\hline
\end{tabular}


Otorhinolaryngological evaluation revealed that of the 22 patients 12 showed inferior turbinate hypertrophy and 11 presented septum deviation (10 of whom showed degrees II and III). Upon oropharynx examination, 12 patients presented uvula edema and 7 uvula stretching, 5 patients had hypertrophied tonsils and 1 had an increased tongue base. Nasofibroscopy during the Müller maneuver revealed obstruction at the level of the velopharyngeal sphincter in 18 patients. Of these, 2 presented obstruction at the tongue base level, 1 at the hypopharynx level, and 1 at all levels.

Polysomnographic findings revealed that patients presented reduced sleep efficiency and superficial sleep, with decreased stages 3, 4 and REM. AHI was above 30 in 13 patients, characterizing moderate to severe OSA (Table 1).

Spirometry, MVV, MIP and MEP revealed mostly normal results for the patients (Table 2). Analysis of the flow-volume curve revealed the presence of sawtooth values in 12 patients and an $\mathrm{FEF}_{50 \%} / \mathrm{FIF}_{50 \%}$ ratio above 1 in eight patients. Analysis of arterial blood

Table 2 - Pulmonary function test and arterial blood gases in OSA patients.

$\%$ : Percent of predicted value, when $\%$ is placed before the variable; FVC: forced vital capacity; $\mathrm{FEV}_{1}$ : forced expired volume during the first second of $\mathrm{FVC} ; \mathrm{FEF}_{50 \%}$ : forced expired flow at $50 \%$ of FVC; $\mathrm{FIF}_{50 \%}$ : forced inspired flow at $50 \%$ of $\mathrm{FVC}$; MVV: maximal voluntary ventilation; MIP: maximal inspiratory pressure; MEP: maximal expiratory pressure; $\mathrm{PaO}_{2}$ : partial $\mathrm{O}_{2}$ pressure in arterial blood; $\mathrm{PaCO}_{2}$ : partial $\mathrm{CO}_{2}$ pressure in arterial blood.

\begin{tabular}{lcc}
\hline Variable & Median & Range \\
\hline$\% F V C$ & 105.5 & $76-133$ \\
FEV $_{1} / \mathrm{FVC}(\%)$ & 81.5 & $68-88$ \\
$\mathrm{FEF}_{50 \%} / \mathrm{FIF}_{50 \%}$ & 0.84 & $0.32-2.86$ \\
$\% \mathrm{MVV}$ & 90.5 & $67-149$ \\
$\% \mathrm{MIP}$ & 112 & $73-162$ \\
$\% \mathrm{MEP}$ & 106.5 & $90-123$ \\
$\mathrm{PaO}_{2}$ & 82 & $56-108$ \\
$\mathrm{PaCO}_{2}$ & 38 & $30-43$
\end{tabular}

gases showed that the patients were all normocapnic (Table 2). The normal group showed values of FVC between 76 and $104 \%$, with $\mathrm{FEV}_{1} / \mathrm{FVC}$ ranging from 79 to $89 \%$.

Comparison of neuromuscular respiratory drive $\left(\mathrm{P}_{.1}\right.$ and $\left.\mathrm{P}_{1} / \mathrm{VCO}_{2}\right)$, respiratory impedance $\left(\mathrm{P}_{.1} / \mathrm{VT} / \mathrm{TI}\right)$, and ventilatory pattern (VT/TI and TI/TTOT) showed no difference between our patients and the normal subjects (Table 3 ).

Figures 1 and 2 show that most patients presented a ventilatory drive within the normal range when it was evaluated by the ratio between the variation $(\Delta)$ of inspiratory occlusion pressure and the variation of $\mathrm{P}_{\mathrm{ET}} \mathrm{CO}_{2}$, before and after the inhalation of a hypercapnic mixture $\left(\Delta \mathrm{P}_{.1} / \Delta \mathrm{P}_{\mathrm{ET}} \mathrm{CO}_{2}\right)$, and by the ratio between the variation of minute ventilation and the variation of $\mathrm{P}_{\mathrm{ET}} \mathrm{CO}_{2}\left(\Delta \mathrm{VE} / \Delta \mathrm{P}_{\mathrm{ET}} \mathrm{CO}_{2}\right)$. Two of these patients, however, presented $\Delta \mathrm{P}_{1} / \Delta \mathrm{P}_{\mathrm{ET}} \mathrm{CO}_{2}$ values $\left(0.11\right.$ and $0.10 \mathrm{cmH}_{2} \mathrm{O} /$ $\mathrm{mmHg}$ ) slightly below the normal range (normal values are between 0.12 and $2.64 \mathrm{cmH}_{2} \mathrm{O} /$ $\mathrm{mmHg}$ ) (17). These patients also presented reduced $\Delta \mathrm{VE} / \Delta \mathrm{P}_{\mathrm{ET}} \mathrm{CO}_{2}$ values (0.94 and 1.09 $\left.1 \mathrm{~min}^{-1} \mathrm{mmHg}^{-1}\right)$, while the normal range is between 1.16 and $6.181 \mathrm{~min}^{-1} \mathrm{mmHg}^{-1}$ (17). The former patient had the most reduced $\mathrm{P}_{.1}$ value at rest $\left(0.8 \mathrm{cmH}_{2} \mathrm{O}\right)$, meaning a reduction of ventilatory drive but without evidence of alveolar hypoventilation. The other patient had the highest BMI value $(39.3 \mathrm{~kg} /$ $\left.\mathrm{m}^{2}\right)$ and reduced MIP $\left(66 \mathrm{cmH}_{2} \mathrm{O}\right)$.

In order to establish whether clinical and polysomnographic abnormalities influence the ventilatory drive, our patients were reclassified based on a cut-off point that corresponded to the median value of hypersomnolence score, sleep efficiency, number of arousals, AHI, and the percentage of total recording time in which saturation remained below $85 \%$. Comparison between subgroups did not reveal any difference in neuromuscular drive $\left(\mathrm{P}_{.1}, \mathrm{P}_{.1} / \mathrm{VCO}_{2}\right)$, respiratory impedance $\left(\mathrm{P}_{.1} / \mathrm{VT} / \mathrm{TI}\right)$, ventilatory pattern $(\mathrm{VT} /$ TI, TI/TTOT) at rest and during exercise or the hypercapnic test $\left(\Delta \mathrm{P}_{.1} / \Delta \mathrm{P}_{\mathrm{ET}} \mathrm{CO}_{2}\right.$ and $\Delta \mathrm{VE} /$ 
$\left.\Delta \mathrm{P}_{\mathrm{ET}} \mathrm{CO}_{2}\right)$.

Also, no correlation was found between the neuromuscular drive and the above variables, except for a weak but significant correlation between $\mathrm{P}_{.1}$ at rest and weight $(\mathrm{r}=$ $0.48, \mathrm{P}=0.02$ ).

\section{Discussion}

Our results point to a group of normocapnic obese OSA patients with ventilatory neuromuscular drive $\left(\mathrm{P}_{.1}, \mathrm{P}_{.1} / \mathrm{VCO}_{2}\right)$ and ventilatory pattern (VT/TI, TI/TTOT) in the normal range at rest and during exercise. Also, the positive correlation between $\mathrm{P}_{.1}$ at rest and weight may indicate a possible load effect stimulation of obesity on the ventilatory drive in our patients. This hypothesis is supported by the study of Sampson and Grassino (5) who described similar results, i.e., a positive correlation between obesity and $\mathrm{P}_{.1}$ values in obese non-OSA subjects. However, when the neuromuscular drive was evaluated by the hypercapnic ventilatory response (HVR), we found normal or slightly reduced values of $\Delta \mathrm{P}_{.1} / \Delta \mathrm{P}_{\mathrm{ET}} \mathrm{CO}_{2}$ and $\Delta \mathrm{VE} /$ $\Delta \mathrm{P}_{\mathrm{ET}} \mathrm{CO}_{2}$, which were not correlated with subject weight. Gold et al. (7) found a reduced HVR in obese OSA patients as compared to obese non-OSA subjects and, since the respiratory mechanics were similar for both groups, the authors postulated that a primary chemoresponsiveness defect may be responsible for the alterations found in OSA patients.

Other authors (8) have shown that normocapnic OSA patients have preserved HVR but a decreased response compared to normal subjects when an inspiratory load is imposed, suggesting that these patients have an altered ventilatory drive, since they did not increase ventilation in response to an inspiratory load. Furthermore, they hypothesized that daytime somnolence was the cause of such abnormality.

The hypothesis that sleep quality of OSA patients can interfere with chemoresponsive- ness during waking is still controversial. Sleep deprivation can lead to altered body temperature, opiate secretion, and daytime hypersomnolence, all of which could explain the inhibition of the respiratory center (13). Studies that addressed this issue also report disputable results. Espinoza et al. (12) did not find changes in HVR in normal subjects following 2 nights of sleep fragmentation. In contrast, White et al. (13) found a $24 \%$ reduction of HVR and a $29 \%$ reduction of the ventilatory response to hypoxemia in $24-\mathrm{h}$ sleep-deprived subjects. Similar results were reported by Cooper and Phillips (11), with a $20 \%$ decrease of HVR in subjects submitted to total sleep for $24 \mathrm{~h}$. The deprivation reported in the above studies and that used here differ in two major aspects: normal

Table 3 - Ventilatory pattern, ventilatory drive and respiratory impedance in OSA patients and normal volunteers, both at rest (Rest) and during submaximal 50-Watt exercise (Ex).

Data are reported as median and range. VT: Tidal volume; TI: inspiratory time; TOT: total time; $\mathrm{P}_{.1}$ : inspiratory occlusion pressure; $\mathrm{VCO}_{2}$ : $\mathrm{CO}_{2}$ output; VE: minute ventilation.

\begin{tabular}{|c|c|c|}
\hline & $\begin{array}{l}\text { OSA patients } \\
(N=22)\end{array}$ & $\begin{array}{c}\text { Normal volunteers } \\
\qquad(\mathrm{N}=10)\end{array}$ \\
\hline \multicolumn{3}{|c|}{ VT/TI (I/sec) } \\
\hline Rest & $0.42(0.21-0.80)$ & $0.5(0.38-0.84)$ \\
\hline Ex & $1.09(0.77-1.47)$ & $1.06(0.63-1.28)$ \\
\hline \multicolumn{3}{|l|}{ TI/TOT } \\
\hline Rest & $0.47(0.35-0.59)$ & $0.39(0.31-0.46)$ \\
\hline Ex & $0.46(0.41-0.56)$ & $0.46(0.41-0.51)$ \\
\hline \multicolumn{3}{|c|}{ Respiratory rate } \\
\hline Rest & $15.1(10.4-27.6)$ & $15.2(10.8-17.5)$ \\
\hline Ex & $24.5(10-49)$ & $20.3(14.1-29.9)$ \\
\hline \multicolumn{3}{|l|}{ VT (I) } \\
\hline Rest & $0.73(0.36-1.18)$ & $0.83(0.57-1.72)$ \\
\hline Ex & $1.45(0.65-2.67)$ & $1.38(0.82-2.17)$ \\
\hline \multicolumn{3}{|c|}{ VE (I/min) } \\
\hline Rest & $12.2(5.4-18.2)$ & $12.5(8.9-23.12)$ \\
\hline Ex & $32.6(23.4-42.3)$ & $29(16.34-35.71)$ \\
\hline \multicolumn{3}{|c|}{$\mathrm{P}_{.1}\left(\mathrm{cmH}_{2} \mathrm{O}\right)$} \\
\hline Rest & $1.5(0.8-6.2)$ & $1.4(0.51-2.42)$ \\
\hline Ex & $4.7(2-14.3)$ & $4.3(2.39-5.60)$ \\
\hline \multicolumn{3}{|c|}{$\mathrm{P} .1 / \mathrm{VCO}_{2}\left(\mathrm{cmH}_{2} \mathrm{O} / \mathrm{ml}\right)$} \\
\hline Rest & $6.1(2.2-14)$ & $4.5(2.12-10.52)$ \\
\hline Ex & $5.1(2.5-12)$ & $4.7(2.32-6)$ \\
\hline \multicolumn{3}{|c|}{$\mathrm{P}_{.1} / \mathrm{VT} / \mathrm{TI}\left(\mathrm{cmH}_{2} \mathrm{Ol}^{-1} \mathrm{~s}^{-1}\right)$} \\
\hline Rest & $3.5(1.4-16.3)$ & $2.9(1.24-4.48)$ \\
\hline Ex & $4.4(2.3-15)$ & $4.5(2.23-6.83)$ \\
\hline
\end{tabular}


subjects were used in all of them and these subjects were sleep deprived for 24-48 h, which is considered an acute deprivation. The HVR obtained for our patients (Figures

Figure 1 - Individual values of $\triangle \mathrm{P}_{.1} / \Delta \mathrm{P}_{\mathrm{ET}} \mathrm{CO}_{2}$ in normocapnic patients with OSA. The horizontal line corresponds to the lower limit of normality at $0.12 \mathrm{cmH}_{2} \mathrm{O}$ $\mathrm{mmHg}(17)$

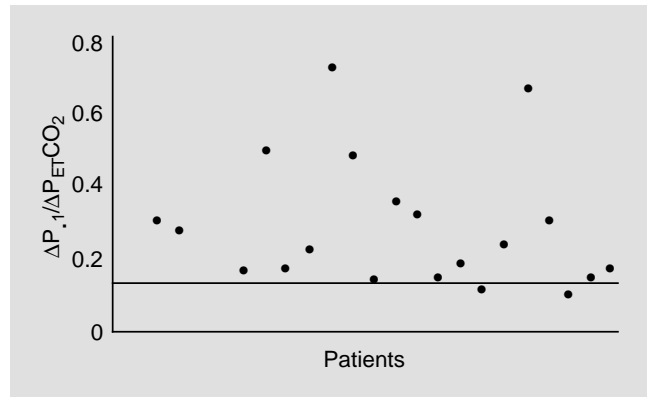

Figure 2 - Individual values of $\triangle \mathrm{VE} / \triangle \mathrm{P}_{\mathrm{ET}} \mathrm{CO}_{2}$ in normocapnic patients with OSA. The horizontal line corresponds to the lower limit of normality at $1.16 \mathrm{I} \mathrm{min}^{-1}$ $\mathrm{mmHg}^{-1}(17)$.

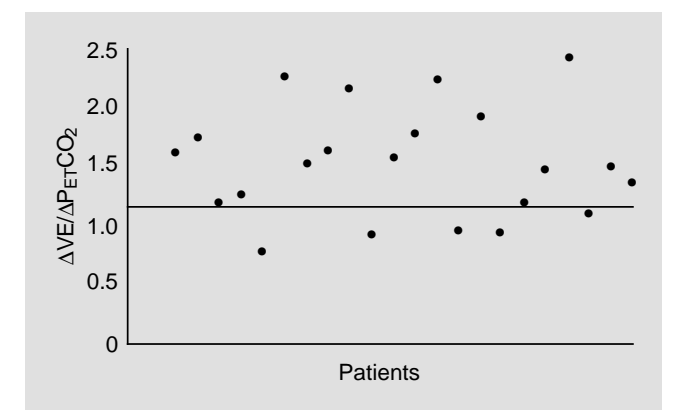

1 and 2) who presented with chronic sleep deprivation and/or fragmentation might be considered blunted, since higher values would be expected, as reported by Gold et al. (7) for obese non-OSA subjects. However, no association or correlation was found between this response and AHI, sleep efficiency, arousals, or hypersomnolence score.

Some studies report an improvement of HVR following treatment of upper airway obstruction by tracheostomy (9) or with the use of nasal CPAP (10) in OSA patients. These results suggest a direct or secondary effect of obstructive sleep apnea reducing the hypercapnic ventilatory drive. Studies utilizing nasal CPAP in OSA patients are currently in progress in our service to test the above hypothesis.

Our results indicate the existence of a group of obese, normocapnic OSA patients who have a normal awake ventilatory drive at rest and during exercise which is partially influenced by obesity.

\section{References}

1. Burwell CS, Robin ED, Whaley RD \& Bickelmann AG (1956). Extreme obesity associated with alveolar hypoventilation: a Pickwickian syndrome. American Journal of Medicine, 21: 811-818.

2. Carrol D (1956). A peculiar type of cardiopulmonary failure associated with obesity. American Journal of Medicine, 21: 819824.

3. Lourenço RV (1969). Diaphragm activity in obesity. Journal of Clinical Investigation, 48: 1609-1614.

4. Zwillich CW, Sutton FD, Pierson DJ, Creagh EM \& Weil JV (1975). Decreased hypoxic ventilatory drive in the obesityhypoventilation syndrome. American Journal of Medicine, 59: 343-347.

5. Sampson MG \& Grassino AE (1983). Load compensation in obese patients during quiet tidal breathing. Journal of Applied Physiology, 55: 1269-1276.

6. Gilbert R, Sipple JH \& Auchincloss JH (1961). Respiratory control and work of breathing in obese subjects. Journal of Applied Physiology, 16: 21-26.
7. Gold AR, Schwartz AR, Wise RA \& Smith PL (1993). Pulmonary function and respiratory chemosensitivity in moderately obese patients with sleep apnea. Chest, 103: 1325-1329.

8. Rajagopal KR, Abbrecht $\mathrm{H}$ \& Tellis $\mathrm{CJ}$ (1984). Control of breathing in obstructive sleep apnea. Chest , 86: 174-180.

9. Guilleminault C \& Cummiskey J (1982). Progressive improvement of apnea index and ventilatory responses to $\mathrm{CO}_{2}$ after tracheostomy in obstructive sleep apnea syndrome. American Review of Respiratory Disease, 126: 14-20.

10. Jones MB \& Sullivan CE (1987). Time course of change in ventilatory response to $\mathrm{CO}_{2}$ with long-term CPAP therapy for obstructive sleep apnea. American Review of Respiratory Disease, 135: 144147.

11. Cooper K \& Phillips BA (1982). Effects of short-term sleep loss on breathing. Journal of Applied Physiology, 53: 855-858.

12. Espinoza $H$, Thornton AT, Sharp $D$, Antic R \& McEvoy D (1991). Sleep fragmenta- tion and ventilatory responsiveness to hypercapnia. American Review of Respiratory Disease, 144: 1121-1124.

13. White DP, Douglas NJ, Picket CK, Zwillich CW \& Weil JV (1983). Sleep deprivation and control of ventilation. American Review of Respiratory Disease, 128: 984-986.

14. Pi-Sunyer FX (1988). Obesity. In Wyngaarden JB \& Smith LH (Editors), Cecil Textbook of Medicine. WB Saunders Company, Philadelphia.

15. Fletcher EC \& Luckett RA (1991). The effect of positive reinforcement on hourly compliance in nasal continuous positive airway pressure users with obstructive sleep apnea. American Review of Respiratory Disease, 143: 936-941.

16. Moura SMT, Sandoval PRM \& Nery LE (1989). O controle e o padrão ventilatório em indivíduos normais e em pacientes com doença pulmonar obstrutiva crônica. Jornal de Pneumologia, 15: 132-138.

17. Burki NK (1989). Measurement of ventilatory regulation. Clinics in Chest Medicine, 10: 215-226. 
18. Nery LE, Neder JA \& Bagatin E (1994). Avaliação da disfunção e da incapacidade secundária a pneumopatias ocupacionais. Jornal de Pneumologia, 20: 182-192.

19. Rechtschaffen A \& Kales A (1968). A Manual of Standardized Terminology, Techniques and Scoring System of Sleep Stages of Human Subjects. Brain Research Institute, Los Angeles.

20. Carskadon MA \& Dement WC (1994). Normal human sleep: an overview. In: Kryeger MH, Roth T \& Dement WC (Editors), Principles and Practice of Sleep Medicine. WB Saunders Company, Philadelphia.

21. Guilleminault C (1994). Clinical features and evaluation of obstructive sleep apnea. In: Kryeger MH, Roth $\mathrm{T}$ \& Dement WC (Editors), Principles and Practice of Sleep Medicine. WB Saunders Company, Philadelphia.

22. Knudson RJ, Slatin RC, Lebowitz MD \&
Burrow B (1976). The maximal expiratory flow-volume curve. Normal standards, variability and effects of age. American Review of Respiratory Disease, 113: 587600.

23. Cherniack PR \& Raber MB (1972). Normal standards for ventilatory function using an automated wedge spirometer. American Review of Respiratory Disease, 106: 38-44.

24. American Thoracic Society (1987). Standardization of spirometry: Update. American Review of Respiratory Disease, 136: 1285-1298.

25. Ringqvist $T$ (1966). The ventilatory capacity in health subjects: An analysis of causal factors with special reference to the respiratory forces. Scandinavian Journal of Clinical and Laboratory Investigation, 88: S5-S179.

26. Wilson SH, Cooke NT \& Spiro SG (1984). Predicted normal values for maximal res- piratory pressure in Caucasian adults and children. Thorax, 39: 535-538.

27. Mellengaard K (1966). The alveolar-arterial oxygen difference: Its size and components on normal man. Acta Physiologica Scandinavica, 67: 10-20.

28. Wasserman K, Hansem JE, Sue DY \& Brian JW (1987). Principles of Exercise Testing and Interpretation. Lea \& Feliger, Philadelphia.

29. Nery LE, Wasserman K \& Andrews JD (1982). Ventilatory and gas exchange kinetics during exercise in chronic airway obstruction. Journal of Applied Physiology: Respiratory Enviromental Exercise Physiology, 53: 1594-1602.

30. Whitelaw WA, Derenne JP \& Milic-Emili J (1975). Occlusion pressure as a measure of respiratory center output in conscious man. Respiration Physiology, 23: 181-199.

31. Siegel S (1975). Nonparametric Statistics. Trilhas, Mexico. 